\title{
Type of Contagion Contact
}

National Cancer Institute

\section{Source}

National Cancer Institute. Type of Contagion Contact. NCI Thesaurus. Code C102723.

Identification and clinical investig ation of disease contacts. 